\title{
Studying the breaches in a collaborative research project in mathematics education: Making sense of the adaptations
}

\author{
Annie Savard ${ }^{1}$ and Dominic Manuel ${ }^{2}$ \\ ${ }^{1}$ Faculty of Education, McGill University, Canada (ORCID: 0000-0002-0285-0952) \\ ${ }^{2}$ Campus Saint-Jean, University of Alberta, Canada (ORCID: 0000-0003-0638-8424)
}

\begin{abstract}
This paper presents a collaborative research project developed by a researcher in mathematics education and a grade 3 Inuit teacher from Northern Quebec. Four learning situations were created, but discrepancies occurred between what was planned and agreed upon by both collaborators, and what was enacted during the project. We studied these discrepancies, which we define as breaches in the research agreement created by both collaborators. We found breaches in three components of the agreement: in the discrepancies between what was planned and what happened during the enactment of the lesson in the resources used, in the pedagogies used, and in the tasks; in the initial roles agreed upon by both collaborators; and in the goals of the collaborators.
\end{abstract}

Keywords: Collaborative research; Research agreement; Adaptation; Representation

Article History: Submitted 4 June 2020; Revised 4 August 2020; Published online 16 August 2020

\section{Introduction}

Teacher professional development aims to improve the quality of teaching and learning in classrooms. Although results from research in education tend to feed the contents presented in professional development seminars, it is often criticized by its weak impact on classroom practices (Goos, 2008). Since the culture and the environment of teachers and researchers are different, it is not enough to study classroom practices and then use the results to inform teachers in a one-day training workshop (Savoie-Zajc \& Descamps-Bednarz, 2007). Empowering teachers in the research process seems a promising way to do professional development with them. Collaborative research can therefore bridge both the academic researchers and the practicing teachers' worlds while constructing new knowledge on classroom practices (Savoie-Zajc \& Descamps-Bednarz, 2007).

This article presents a collaborative research initiated by a researcher in mathematics education (the first author), who is described as the researcher, and a grade 3 Inuit teacher from Nunavik, a circumpolar region in Quebec, who volunteered to participate in the project. This region suffered badly from the white colonialism. As it was explained to the researcher, in order to stay close to

Address of Corresponding Author

Department of Integrated Studies in Education, Faculty of Education, McGill University, 3700 McTavish Street, Room 309, Montréal, Québec, Canada H3A 1 Y2.

$\triangle$ annie.savard@mcgill.ca

How to cite: Savard, A. \& Manuel, D. (2020). Studying the breaches in a collaborative research project in mathematics education: Making sense of the adaptations. Journal of Pedagogical Research, 4(3), 165-186. 
their children, those nomad populations decided to settle down near to the schools built by white people. Since 1978, Inuit have their own educational curricula that aim to celebrate their culture, which is grounded in their need to survive in the northern part of Quebec. Children learn in Inuktitut, their first language, for the first two years of school and then in a second language, either French or English for the remainder of their school years (Daveluy, 2008). These cultural differences, compared to the rest of Western Societies, present many challenges with some mathematical concepts such as probability, because this concept is defined qualitatively and not quantitatively in their culture. The teacher felt she needed to learn more about mathematics and made that her main goal for the collaborative research project. The researcher's initial goal was to study grade 3 Inuit students' probabilistic reasoning. However, some discrepancies occurred between what was planned and agreed upon prior to and during the enactment of the learning situations created for this project. The teacher and researcher's worlds were so physically and culturally different that we saw a need to look closely at those differences by studying both collaborator's learning intentions, representations, and actions during the classroom enactment. Yet, those cultural differences might not explain everything in this collaborative research project. The researcher thus added a second goal for herself in the research project: to study the discrepancies between what was planned and agreed upon and what happened during the enactment and make sense of the adaptations made by the collaborator. This article presents findings from her last goal.

\subsection{Doing Research with Teachers}

According to Raymond and Leinebach (2000), collaborative research gives teachers the opportunity to study problems that they observe in their classrooms working hand in hand with a researcher. Teachers are collaborators throughout the process and not research subjects (Desgagné, Bednarz, Couture, Poirier, \& Lebuis, 2001). They thus need to be initiated to research, and be considered as partners (Wittmann, 1998). Deblois (2009) defines collaborative research as a shared construction between teachers and researchers that allows finding answers to important questions for all involved, even if they are different for all collaborators. This is thus not a hierarchical relationship since each collaborator 's contribution is equally valuable.

Desgagné (2007) identifies three phases in a collaborative research. The first phase is named the co-situation of the project and allows teachers and researchers to define their roles and identify the goals for the project. Together, all the collaborators must define how the project will be developed, when and where it will take place, and decide their roles, actions and responsibilities. The collaborators negotiate their engagement in this phase and plan out the project itself, including the resources needed (funding) and the collection of data. All the collaborators' expertise should be used during the project elaboration. For instance, the researcher is likely the content expert, but the teachers know the specific conditions of their classroom (Wittmann, 1998). Political, professional and school contexts can help or compromise the elaboration part of this phase (DeBlois, 2009). The second phase is the cooperation phase, where the action through the implementation of the planned project, takes place, including the data collection. All the collaborators engage themselves in the implementation of the project and take on their respective roles and responsibilities that were agreed upon in the co-situation phase. Reflection sessions between the collaborators are also crucial throughout this phase to get a better grasp of what is happening at different points in the project, share possible issues and challenges, and discuss possible adjustments and improvements if necessary. This back and forth cyclical thinking process about teaching experiences and reflections creates an interpretative zone, which represents the core of the collaborative project. It is an authentic encounter between collaborators and thus, the cooperation is an essential component of the third phase: the co-construction. The co-construction phase constitutes constructing new knowledge by analyzing the data collected in the previous phase. This new knowledge should reflect the needs and preoccupations of all collaborators from both research and practice perspectives. Teachers can be involved in the analysis of the data and the diffusion of the 
results. However, given the fact that teachers are not trained as researchers, they do not always participate in this phase (McIntyre, 1997), but their collaboration in the two previous phases influences this one.

The main challenge of collaborative research is to create a space where researchers and teachers share their expertise to meet their particular needs (Deblois, 2009). A team led by Jaworski (2005) studied the processes involved in collaboration between mathematics teachers and didacticians (Goodchild, 2007; Goodchild \& Jaworski, 2005; Jaworski, 2005, 2007; Jaworski \& Goodchild, 2006). Inquiry communities were created to support mathematics teachers in implementing inquiry approaches in classrooms. All partners worked together in designing tasks for workshops and for classrooms. The specialized expertise of the teachers and the didacticians were recognized and their needs were defined. The expertise of the teachers was about the knowledge they had of their students and of the schools while the expertise of the didacticians was more on the theoretical knowledge they had about inquiry. The needs of the collaborators were different. The teachers wanted to fulfill their specific needs related to learning inquiry approaches in classrooms while the didacticians needed to learn about issues that have to be addressed throughout the project (Jaworski, 2005). The didacticians planned the workshops in ways that responded to the teachers' needs. The teachers designed lessons with the assistance of the didacticians and implemented them in their own classes and the didacticians observed in them (Goodchild, 2007). Results showed that the collaborators from the schools were not always satisfied by the responses perceived by the didacticians, since they would have preferred to have a certain kind of contribution from them (Jaworski, 2005). The teachers also perceived a contradiction; the didacticians were taking leadership and a more authority role in the project (Goodchild \& Jaworski, 2005). This result shed some light on the necessity for collaborators to explicitly express their role, their goals and their needs.

Needs can be met explicitly, especially if they are targeted by instructional goals or learning intentions aimed in the project. Those intentions are in fact goals pertaining to subject matter that they want their students to achieve (Ball \& Forzani, 2009). The teachers' learning intentions can also include goals from a learning situation identified in textbooks, namely the instructional goals of a lesson. These instructional goals are the ones identified in a learning situation by the developers of the problem or activity, which are in fact the developers' intentions behind the situation (Hirn \& Viennot, 2000). The teacher's learning intentions can be the same as the instructional goals of a situation but can also differ and be very specific ${ }^{2}$. The researcher's previous work (Savard, 2012) showed that elementary school teachers' intentions were influenced by their sensitivity to their milieu (Savard, 2012, 2017). The sensitivity to the milieu is defined by Deblois (2006) as components of the school environment and system that draw the teacher's attention. For instance, the teachers that the researcher worked with were more sensitive to their students' characteristics rather than the mathematical tasks embedded in the science and technology learning situations.

\subsection{The Research Agreement}

As mentioned above, the collaborative research process between teachers and researchers can be seen as a research agreement. This agreement created in the co-situation phase is maintained throughout the whole project. A first component of the research agreement takes into account the definitions and the institutional responsibilities of each collaborator. For teachers, it implies a formal engagement because they have to agree to participate. In some cases, they might need to get the approval from the school principal, the school board, and possibly the community (which was the case for this project). They have to get the consent from the children's parents. It involves a commitment since they have to give some time and energy, and be willing to try things out. It might imply to be recorded and interviewed. It also implies a formal engagement from the

\footnotetext{
2 Teachers might have goals for themselves. In this case, we refer to them as professional goals.
} 
researcher: to be committed to the success of the project by creating the best conditions for the collaborators. The research agreement might involve funds: funds to pay for materials, substitute teachers, meals and transportation. This is usually a part of the researcher's responsibilities, although in some cases, it might be the teachers who receive funds. The researcher is also responsible for getting the ethical approval for conducting the study, and must communicate the results at the end of the project. This first component of the research agreement also takes into account the collaborators' respective environments. Each collaborator considers and values the political, professional and other aspects that they might be sensitive to in their milieu, or elements that might have an impact on the project. A second component of the research agreement is describing the goals and needs of each collaborator involved in the project. In the co-situation phase, the collaborators share their goals and plan out main ideas as to how they will achieve them. These goals must be kept in mind throughout the project. The third component is the shared vision of the project. It involves negotiating the final product and planning its design and implementation or enactment. For our study, our shared vision was to create learning situations that bridge traditional Inuit culture and Mathematics. A fourth component of the research agreement is defining the roles and responsibilities for each collaborator during the steps of the project. It is possible that one collaborator might have more responsibilities, but consultations with the other collaborators must be made.

Some parts of the research agreement might however still stay in the shadows because of an implicit side such as the perceived expectations between the teacher and the researcher through the research project. Thus, even if the collaborators know the goals of the project, they might perceive different expectations from each other collaborators. Some breaches might occur. The research agreement is not hierarchical between the collaborators: both collaborators bring different expertise in this partnership. The researcher is the one accountable for the project: he is responsible for the budget received from grant agencies, ethical considerations, and has to make sure that all steps of the project are done in the best conditions. He might also be perceived as the content expert. The teacher is responsible for her students: she/he has to make sure that they will receive the best learning conditions during the research project. The teacher is considered the expert in his/her school environment.

Given the fact that the collaborators are coming from different worlds, the research project and the research agreement might be perceived differently by them: they may have different representations about them. We consider representations as an intersection between the knowledge mobilized and the situation (Brun \& Conne, 1990). Thus, representations not only include the research project and the research agreement; they also include interpretations of the instructional goals of a learning situation and the involved content in the situation. Indeed, the teacher's representation in regard to mathematics and teaching guides her practices (Brun \& Conne, 1990) and thus, her learning intentions. Since the milieu is what the teacher and the researcher focus their attention on, we consider that the sensitivity to it as a component of the collaborator's representations. What they are paying attention to in their milieu and how they interpret it forms representations. The researcher and the teacher have different milieu and different representations, even if the project is common to both. The milieu for the researcher might be the teacher teaching in class while the milieu of the teacher might be the enactment of the lesson with students. At the same time, each collaborator plays different roles in the three phases of the collaborative research. Their actions are defined in regard to the goals of the project. But the research agreement might be broken at certain points. Consequently, we consider a breach in the research agreement as a change or a decision that is made prior or during the project without the agreement of all collaborators. In fact, a breach is an adaptation to what the collaborators pay attention in their milieu as a response to their representations.

DeBlois and Maheux (2005) studied the adaptations made by two pre-service elementary school teachers during their field experience in a collaborative research project. Two groups consisting of the pre-service teachers, their cooperative teacher(s), and the school's special education teacher 
were created, and they met with the researchers. They met to plan lessons, and then after the enactment to reflect on them. The researchers studied the gaps between what was planned and what was enacted in class. They identified four types of adaptation: projective, withdrawal, normative and avoidance. Projective adaptations appeared when the pre-service teachers used what students say to further enhance the discussion by questioning them. Withdrawal adaptations were seen when the pre-service teachers stepped back to leave students more space to solve some difficulties they faced. Normative adaptations appeared when the pre-service teachers intervened to adjust the students so they could adapt to a good answer. Avoidance adaptations were observed when pre-service teachers simplified the task and lowered their expectations toward students. Thus, the problem might have gotten totally eluded. All the adaptations aimed to support students in the learning process as planned. In fact, both pre-service teachers' main concern was to enact the situation according to what was planned.

In this article, we are interested in studying the breaches in the research agreement. In many occasions, discrepancies occurred between what was planned and agreed upon and what was really done throughout the whole project for both collaborators. As research goals, we want to know what the breaches in the research agreement are, where they came from and the reasons why the collaborators felt the need to adapt what was originally established.

\section{Method}

\subsection{Research Design}

In this section, we present the research design according to the three phases of collaborative research presented in our framework.

\subsubsection{The co-situation phase}

During the co-situation phase, which began in spring 2010, the researcher had many meetings with the teacher and three school board consultants. The teacher could not always be present during the meetings, because she had to be in class. Although funds from the research grant were available to hire a substitute teacher, nobody was available to substitute during those days. The teacher came when her students were not in class. The three school board consultants helped the researcher to have a better understanding of the Inuit culture. The discussions were very important for the researcher, because she was a Quallunaat, a white and non Inuk person in a post-colonialist region (Berger \& Ross Epp, 2006). They discussed their traditional culture and the way Inuit people learn. Traditionally, Inuit learn by observation of phenomena in their surroundings. They have to observe and think to make sense based upon certain factors. A more experienced person, usually an elder in the community, also guides them. Making mistakes is not well perceived since living up North relies on survival skills, such as: reading the weather, walking on ice, fishing, and hunting. Therefore, mistakes could lead to lack of resources, such as food that are necessary for survival.

This information were capital to the researcher, because she wanted to bridge their traditional ways of learning to a mathematical concept that was developed in Western Societies, probability. This mathematical concept should be taught in their schools because it appears in the provincial curriculum. Although teaching and learning probability in school might be perceived as imposed vision of the western view of mathematics, the researcher firmly believed that understanding probability is needed for all citizens in this complex world (Savard, 2015). She argued that all people should have the keys to understand and navigate in the world in a way that promotes their autonomy, their dignity and their rights (Savard, 2017). As pointed out by Stavrou \& Miller (2017), she hoped that her work and discourse would support social justice issues in regard to decolonizing and anti-oppressive movements. However, the researcher was conscious to have implicit biases that might influence her vision of the projects and the results of it.

In their meetings, the school board consultants also presented some traditional games elders played many years ago. The researcher realized that it was possible to study the concept of 
probability using some games and then design a sequence of learning situations using them. As mentioned previously, the views of probability within the Inuit culture differ from the one used and developed by western society. Thus, this study could meet another challenge in learning from the Quebec curriculum. For instance, the game called Inugait is a traditional game known in many parts of northern Canada that reproduces Inuit's traditional way of living using seal bones. Each different seal bone represents a particular character (human or animal) or an object in the game: a man, a dog or a sleight. Following an introduction of the Inugait game to the students, other games using the same seal bones were planned. When the researcher and the teacher discussed between the meetings with the school board consultants, they identified and explicitly shared their research goals as well as their roles. They established the research agreement. The researcher's initial goals for this project were to conduct a study on the development of probabilistic reasoning with grade 3 Inuit students, and on the development of critical thinking skills in respect to gambling activities. Probability is a mathematical concept that is not explicitly defined by the traditional Inuit culture. However, they have a notion of uncertainty and variability, which are needed concepts to understand to live on the land where the weather changes dramatically (Savard, Manuel \& Lin, 2014). The teacher's goal was to learn more about mathematics. She mentioned during the first meeting that she felt the need to know more mathematics in general.

After learning about traditional games and seeing their potential in developing probabilistic reasoning, the researcher created four learning situations based on those games while taking to account both her and the teacher's learning goals. The teacher didn't want to take the lead in creating the learning situation, but the researcher always consulted her and asked for her comments and suggestions while elaborating them. The teacher was always willing to try new things. The researcher expected that the teacher would participate more during that phase, but she respected her decision and made sure that she was comfortable with the design. The teacher proposed to create some material, such as a bones chart to guide students during the learning situations, and bone cards that would be used in one of the learning situations. She also volunteered to get the seal bones. Her husband hunted and killed a seal. She cooked it and collected the bones needed for the project. Inuit eat seals; it is a traditional way to get food and material (for clothes) for them. It is still an important aspect of their life.

The learning situations were created following the researcher's ethnomathematical model (Savard, 2015) where mathematical learning situations should be located in sociocultural aspects, then mathematical and finally citizenship contexts. The citizenship context was represented by the life in the Inuit community, using critical thinking as a tool for living and surviving in the North. The learning situations were anchored in traditional Inuit culture through games, which served as the sociocultural context of the situations. Some important mathematical ideas about probability were identified to help students learn and represent the concept in each learning situation. For instance, qualitative language such as possible and impossible was targeted in the design of the situation. Other important ideas included: theoretical probability and frequential probability, equiprobability, variability, randomness sample space and uncertainty. Studying students' conceptions about random phenomena was also targeted. The first learning situation was called Inugait and students were to explore the qualitative probability of different seal bones to stand up right when they were thrown in the air. The second learning situation called Wishing Song focussed on various conceptions about probability. In this activity, students had to sing a traditional song, throw one big seal bone and note the result (if it stood up right or not). According to traditions, the wish is made before throwing the bone, and it is supposed to come true if the bone stands up right. The third learning situation was called Sauniit and focussed on the concept of equiprobability. Students had to experiment with frequential probability by choosing a bone card from a mitten. In this activity, the bones were drawn on cards (one bone per card) that all have the same dimensions. The last learning situation, Makitaguq, was similar to the third learning situation, except that students experimented with a die and compared the frequential probability with the theoretical one. This activity would also highlight the law of large numbers. For more 
details about the learning situations, see Savard et al. (2014). After the learning situations were created, the researcher discussed them with the teacher and made minor adjustments according to the comments and suggestions that came out during the discussion. The researcher kept a field journal of all the discussions made at each meeting. Most of those meetings were also audiorecorded.

\subsubsection{The cooperation phase}

The collaborators met again in November 2010 and February 2011 for the cooperation phase of the project. During those times, the teacher enacted the learning situations with her 15 students. In October 2011, prior to the cooperation phase of the project, the teacher taught some lessons about the sociocultural aspects of the learning situations that involved the traditional game Inugait, which was the strong cultural aspect of the four learning situations. This was done to prepare the students for the learning situations that were to come. Those lessons were not recorded, and the researcher was not present at that time. Table 1 summarises the whole learning situation Inugait. The first column contains the phase of the learning situation (preparation, introduction, realisation and conclusion), the context according to Savard's (2015) ethnomathematics model, and the goals for the phase and context. The steps taken by the teacher are presented in the second column.

Table 1

Description of the learning situation Inugait

\begin{tabular}{c}
\hline $\begin{array}{c}\text { Phase of the activity (context) } \\
\text { and instructional goals }\end{array}$ \\
\hline $\begin{array}{c}\text { Preparation for the learning } \\
\text { situation }\end{array}$ \\
\hline
\end{tabular}

Steps taken by the teacher

Preparation for the learning 1 . Collecting the seal bones with her mother and her best friend's mother. Her husband killed the seal.

2. Elders come to class to present the game and Inuit culture to students.

3. Showing half of the movie on Inugait to students on how to play the game: how to pull the bones from the mitten and put them on the ground.

\section{Introduction \\ (Sociocultural context)}

Instructional goals:

1. Knowing the names and characteristics of each bone so students don't mix them up. Some look almost the same.

2. Being efficient at catching the bones. If they are not fast enough, they will not catch any.
4. Making an Inugait bones chart for supporting students in knowing the names and characteristics of each bone.

5 . Teaching the bone chart to students and learning the song that comes with the game.

Demonstrating how to catch the bones. Teaching the importance of catching the bone representing a seal (more seals $=$ better survival).

6. Making a homework assignment sheet on the bones.

7. Asking parents to help children learn the name of the bones.

8. Bringing the old chart to class (this chart contains the bones and their signification in the game).

9. Reviewing the first bone chart and correcting the assignment sheet.

10. Letting students play the game (catching bones).

11. Letting students play the game and building their camp.

12. Asking students to write the names of the bones they caught sot hey can write a story about them later on.

13. Showing the rest of the movie.

14. Letting students practice the song and play the game and

Realisation

(Sociocultural context) count how many seal bones they catch. Making sure that students know the importance of the seal for survival in North. 
Table 1 continued

Phase of the activity (context) and instructional goals

\section{Steps taken by the teacher}

Realisation
(Mathematical context)

15. Letting students sing the song and throw a bigger seal bone and note if it stands up right or not.

16. Letting students throw all the bones and note the outcomes.

Instructional goals:

1. Observing the variability of

the outcomes.

2. Study students' conceptions

on the variability of the

outcomes.

$\begin{array}{cl}\text { Conclusion } & \text { 17. Concluding by asking if it is possible or not to have bones } \\ \text { (Mathematical context) } & \text { stand in different ways and why? }\end{array}$

Instructional goals:

1. Knowing what students

think about the variability of

the outcomes.

2. Study students' use of the

qualitative vocabulary in

probability.

The first 13 steps were done without the researcher. However, the material developed by the teacher and the students' works on the name of the bones were later presented to her. When the researcher was in the classroom for steps 14 to 16 (see Table 1), she noted that the students were able to recognize and name the bones with assistance and sing the chant. During the implementation of the learning situations, the researcher was present in class as an observer and video-recorded the enactment of the learning situations. The researcher also took notes in her field journal. Both collaborators met before and after each lesson in order to debrief, reflect and plan based on what happened during the enactment. Some of those meetings were audio-recorded.

\subsubsection{The co-construction phase}

The co-construction phase focused on analyzing the data collected. The teacher was invited to participate in this phase, but she denied. Instead, she decided to write a book on traditional Inuit games. Since the researcher had two new doctoral students during that time, she invited them to participate as research assistants in the data analysis and the writing of articles. Both doctoral students accepted the invitation and one of them is a co-author of this article. This step helped the researcher distance herself from the project since her actions would also be analyzed. Multiple discussions took place between the research assistants and the researcher. This helped them understand the project rationale and analyse the researcher's actions, goals and interpretations during the whole process. They took notes during the discussions.

\subsection{Data Collection Tools and Analysis}

The researcher got the ethical approval from her institution before approaching the school board and the community. A grade 3 Inuit teacher accepted to participate in this project she taught every subject to a class of 19 students in their first language. This collaborative research was conducted during three non-consecutive weeks. The first was during spring 2010, the second in November 2010, and the last one in February 2011.

Regarding the data collecting tools, we used the written lesson plans of the learning situations that were agreed upon by the collaborators, the videos of the enacted lessons, the audio-recorded 
interviews, and the researcher's field journal. All the videos were translated from Inuktitut to English by a professional translator. This process was also video-recorded so that the researchers could observe what was going on in the video while it was being translated. The research assistants then transcribed the translated videos.

To study the breaches in the research agreement, we first took the lesson plans that were agreed upon for the four learning situations. We carefully watched the videos of all the lessons being enacted and took notes of all the discrepancies between what happened in the videos and what was written in the lesson plans. We specially looked for: elements present in the enacted but not on the lesson plans; elements present on the lesson plans but not in the enacted lessons; and changes in the goals and the roles of both collaborators. We also looked at the researcher's field journal for breaches in the research agreement. The researcher did record each step of the research process, including what was happening in the classroom and teacher rationale of her actions. Doing this last step helped us be aware of modifications made in the lessons along the way. The videos helped us identify the actions taken by the teacher and her students and compare them with the lessons plans. The field journal helped us identify explanations or adaptations that caused a breach by the teacher or the researcher, topics discussed during the meetings, and modifications made in the enactments. After watching the videos, we listened to all the audio-recorded interviews between the researcher and the teacher. This helped us identify the adaptations made by the teacher or the researcher, the teacher or the researcher' intentions and representations of the learning situation. Since the researcher was not always present in the videos (she was filming), the research assistants needed answers about the researcher's learning intentions and representations of the situations at some points of the enactment. One of the research assistants thus conducted follow-up interviews with the researcher and took notes of the discussions.

The results will be presented for the cooperation phases of this collaborative research project. We did not ignore the co-situation phase where the collaborators defined their goals and their roles. There was room to change and to adapt them prior to the enactment of the learning situation in class. We did not observe any breaches in the research agreement during the co-situation phase.

\section{Results}

Our analysis revealed various breaches in three different components of the research agreement. First, we observed discrepancies between what was planned and what happened during the enactment of the lesson. These discrepancies were observed in the resources, the pedagogies and the tasks used during the lessons. Second, we observed changes in the initial roles agreed upon by both collaborators. Third, the collaborators changed their goals during the collaborative project. We discuss each component in the following subjections. Different types of adaptations were made depending of the breach. We discuss the impact of those adaptations focussing on the student's learning of probability. We present the collaborator's learning intentions and representations of the situation that influenced the adaptation.

\subsection{Breaches in the Lesson Planned and Enacted}

Throughout the enactment, two breaches in the research agreement appeared in the choice of the resources used. In both cases, the teacher made what we call a substitute adaptation: a substitution of the material being used. This substitute adaptation was considered minor, because it did not influence the student's learning of probability. In the first case, the collaborators agreed to invite Elders to come to class and present the game Inugait and their traditional lifestyle. Elders refused to come, so the teacher introduced the game using a book that explained the game. The teacher was sensible to the sociocultural aspects of the learning situation. Her learning intention was that her students learn about the game and their traditional lifestyle, thus doing what was planned. Her representation of the situation was that the game represented an important knowledge that young Inuit didn't know about. The change of resources did not affect the instructional goals of the learning situation because it remained aligned with what was planned. The teacher stayed in 
the sociocultural context like it was planned. In the second case, still in the learning situation Inugait, the collaborators planned to have students learn and sing a traditional song. The singer had to make a wish at the end of the song and then throw a seal bone. According to their traditions, if the bone stood up right, then his wish would come true. After the song, it was planned to do an experiment with the bone to study students' conceptions on probability. For this, the collaborators agreed to show the students a video. The teacher wanted to show the video to help her students sing the song because she said: "I don't know how to sing it" (Interview with the teacher). The video didn't work because of technical issues, so the teacher asked a school board consultant to come to class and teach the song. The teacher was sensible to the sociocultural aspects of the learning situation. Her learning intention was that her students learn and sing the traditional song, thus doing what was planned. Her representation of the situation was that the song represented an important knowledge that young Inuit didn't know about. Again, the change of resources did not affect the instructional goal of the learning situation because it remained aligned with what was planned. The teacher stayed in the sociocultural context: the mathematical context was not supposed to be targeted at that point.

Another breach in the research agreement appeared in the pedagogical choices related to classroom management used during the lessons enacted. The teacher made an avoidance adaptation, meaning that she did something different than what was planned and agreed upon. This type of adaptation might be perceived as minor, but it wasn't due to the nature of the task, which was to study frequencies by having a large number of trials. The collaborators agreed that, in the learning situation Wishing Bones, the students would be divided in four groups and do an experiment with a seal bone. The Students would have to throw the bone 100 times and write the frequency of the way it fell: standing up right or not. However, the teacher had them working as a whole group and didn't ask them to do the experiment 100 times. Instead, she kept asking students to predict if the bone would stand up right or not, and then asked them why it stood up ${ }^{3}$. The teacher was sensible to the sociocultural aspect of the learning situation, particularly on the seal bone and why it stood up. Her learning intention in this case was that her students learn about this knowledge instead of the frequency. Her representation of the situation was that this knowledge was important. She even mentioned during an interview that she asked Elders in her community about these traditions because she wasn't familiar with them. However, she didn't see the law of large numbers in the lesson because she did not pay attention to the number of trials, and in her mind, her learning intentions were aligned with the task. The adaptation in this case was considered as major. The change affected the instructional goals of the learning situation because it was not aligned with what was planned and thus modified the learning opportunity. The teacher stayed in the sociocultural context and did not reach the mathematical context.

Other breaches in the research agreement were found in the tasks enacted during the lessons. The teacher made three structural adaptations by totally changing the tasks without discussing them prior with the researcher. Those changes were made before the enactment and they modified the structure of the learning situation. We considered them as major adaptations because they enabled students' opportunity to learn about probability. The teacher changed the task the first time in the learning situation Inugait. The collaborators agreed that the students would do an experiment with the bones. Each student had to throw a bone 10 times and write down the number of times the bone stood up right. The teacher was supposed to compile all the result for every student (number of times the bone stood up out of 10) on the blackboard and then orchestrate a discussion about the results. Instead, she put all the bones in a heap on the floor and each student drew (picked) a bone. Then, they put all the bones together and she asked two students to search and find the bones that

\footnotetext{
3 The bone had an irregular shape, which means that it was not equiprobable. It was not possible to tell the theoretical probability of the bone; the frequency is the way to determine the probability to stand up right or not. Discussion about standing up might lead students to express alternative conceptions and later on, in another learning situation, compare the bone with a die. They can learn about equiprobbaility.
} 
represented the seal. The students had to align the bones they found and count them at the end, and the one who found the most won. The teacher was sensible to the sociocultural aspect of the game Inugait, which was to play with the bones using their characters. She mentioned: "It is hard to explain, if I not explain how to play, it is hard. It is like learning poker. You don't know how to play poker, you learn first how to play, same thing with Inugait" (Interview with the teacher). Since it was difficult for students to learn this game without being familiar with the bones and their names, her learning intention was that her students learn to recognize each bone involved in the Inugait game, especially the one representing the seal, one of the most important characters of the game. Traditionally, the seal provides food, and its skin can be used to create material like clothing to survive. It is an important animal in the Inuit culture. She also had another learning intention, this time toward mathematics. She wanted both students playing the game to count the bones they found and say who had more. During an interview, she mentioned that she wanted to give her students the opportunity to do this because some of them had difficulty with subtraction. Her representation of the situation was that the learning situation consisted of an opportunity to recognize the bone representing the seal among the others. She did not recognize the mathematical idea of randomness in the task; she saw a skill game where students could select a particular bone in a collection, and that the winner was important. Skill games are important in the traditional Inuit culture. To survive in these regions, people must be good at fishing and hunting. Playing games was a way to develop physical skills. This first change affected the instructional goals of the learning situation because it was not aligned with what was planned and thus prevented the opportunity for students to learn about probability. But it seemed as though the teacher thought that her actions were aligned with what was planned because she said in an interview that she did mathematics during the activity. The collaborators were clear that the project was about studying Inuit culture using mathematics, more specifically the concept of probability. Some mathematical operations were used during the task, but the mathematical aim on probability was avoided. Yet, the teacher stayed in the sociocultural context of the situation and was not able to bridge the mathematical context on probability.

After the enactment of this activity, the collaborators met and decided to try it again, but with some changes. The students would have to throw two bones 10 times, count the frequencies of each bone (that stood up right or not) and compare them. Again, the teacher was supposed to compile all the results for each student on the blackboard and orchestrate a discussion about them. The teacher changed the task a second time. She asked a student to throw all the bones on the floor. That student along with another had to search and find all the bones that stood up right. They had to align them together according to their names (the characters they represented in the game) and count them. The student who found the most won. After that, two students sang the song and each threw an identical bone at the same time. The student whose bone stood up right would win. Each pair of students played five times. After observing this for a few minutes, the researcher didn't understood what was going on because of the language barrier, so she asked the teacher to write down the results on the blackboard. She wanted the students to be able to see the results and compare them. The teacher wrote the result on a sheet of paper and then said to the students that the first one to come up with five bones standing up right would win. She also mentioned that the winner would be allowed to choose a woman that would be his wife. The teacher was sensible to the sociocultural aspect of the situation; particularly on the bones and the ones stand up most. The learning intention she was targeting was that her students learn about how a bone would stand up right and how it would not. Her representation of the situation was that it was important to know how bones stand up right and which ones do it more often. She thought that it was an important traditional knowledge because Elders knew about it. Having a winner was also very important because the winner could choose a "good wife who will sew warm clothes for him" (Interview with the teacher). This change also affected the instructional goals of the learning situation because it was not aligned with what was planned, thus enabling the chance for students to learn about probability. Again, it seemed that the teacher thought that 
what she did was aligned with what was planned because some counting was involved. The mathematical aim on probability was avoided since the teacher stayed in the sociocultural context of the situation and again was not able to bridge the mathematical context on probability.

The teacher changed the task a third time while enacting the learning situation named Sauniit. Students had to study the idea of equiprobability using small bone cards. The teacher made cards of the same dimension, which is an important aspect for learning about equiprobability. Some cards had the picture of one bone, while others had the name of a bone written either in syllabics or in Latin alphabet. This was what the collaborators agreed upon. First, the teacher would put a certain number of cards in the mitten making sure that only one card of the same bone was in it. Second, the students would draw one card, name the bone on the card, and put a tally on a table on the blackboard next to the bone he drew. Third, the student would then put the card back in the mitten and the next student would repeat the same procedure. When all students had two turns, the teacher would help them count the number of tally for each card. Finally, the whole class would discuss the equiprobability based on the shape of and the number of cards in the mitten. In a second task, the students were supposed to find out the frequency of the cards using five bones cards in the mitten, each card having a different bone on it. Together, they would draw a card 100 times and compile the results. The goal of this was to compare the frequential probability to the theoretical one. The teacher changed the task a third time by having her students make pairs using the cards containing the names of the bones in syllabics and the ones in Latin alphabet. Each student picked a bone from a mitten or a bag. The teacher then presented the cards to the students and distributed three cards to each of them. The students had to first say the name of the bone on their cards with the help of the bone chart on the wall or the book that the teacher showed. They then were asked to make pairs with the cards they had by picking a card from their neighbour. After the game, they had to put their pairs in the middle (students were sitting in a circle), and each student would have to associate the bones they picked at the beginning of the activity with the pairs in the middle. The teacher was sensible to the sociocultural aspects of the situation, in particular the fact that students had to know the name of the bones to play Inugait. Her learning intentions were that her students be able to: recognize and name the bones, and associate the written names in syllabic and in Latin alphabet of those Inuktitut words. Her representation of the situation was linked to poker. The teacher even mentioned that she went to a casino during her winter holidays so she could be more prepared to teach this learning situation on probability. She wanted ideas to introduce card games. In fact, she associated probability to poker. For the teacher, having students pick cards and making pairs like in poker was doing probability. Her learning intentions were aligned with that task. She tried to reach the mathematical context, but her representation of probability left her in the sociocultural context.

Other breaches were observed when the teacher totally avoided elements that were agreed upon in the lesson plans. We consider them as extreme avoidance since the neglected elements that were important for mathematical learning. For instance, in the learning situation called Inugait, she did not ask her students to draw a card 100 times. Also, she did not have them compile the results and discuss them. Those avoidance adaptations were major and put the project at risk in terms of learning probability. The teacher was sensible to the sociocultural aspects instead of the mathematical aspects of the situation. Her learning intentions were possibly aligned with her representation of the situation. We assume that she thought she followed everything that was agreed upon in the project, because she was genuinely receptive to the project and was willing to spend time and energy to it. She said that the whole project is mathematics (interview with the teacher). Her representation of probability might have misled her and prevented her from reaching the mathematical context.

\subsection{Breaches in the Roles Planned and Enacted}

The collaborators' roles changed during the enactment. Breaches between what the collaborators agreed upon as the roles they would play in the project and the roles they played during the 
enactment appeared for both collaborators. The teacher changed her role two times during the enactment. The first time was at the beginning of the enactment of Inugait. She initially refused to be video-recorded, because she was not comfortable with it. Thus, she asked a teaching assistant who was assigned to help a student with behavioural problems to teach in front of the camera. The teacher helped the assistant on the side. The students needed to know how to use the string for this learning situation, but the assistant couldn't demonstrate it correctly. Therefore, the teacher came in front of the students and the camera and explained it to her students. The camera did not move: the teacher came in front of it purposely. It was possible for the teacher to ask students to come to her side and then teach them. Instead, she went in front of the camera. After the lesson, the researcher again asked for her permission to be video-recorded because of what had happened, which she agreed and signed the consent form. The teacher was sensitive to the sociocultural context of the game. Her learning intention was to support her students in learning how to use the string to draw bones from the mitten. Her representation was that students needed visual support, a demonstration in this case, to learn. Changing her role seemed to be a minor adaptation for the research project, but was possibly considered as a major one in terms of students' learning.

The teacher's role changed a second time when she designed a completely new task. In the cosituation phase, the teacher wanted the researcher to create a first draft of the learning situations and then she would add things to them, consulting them with the researcher. In this case, she created the task without discussing it with the researcher. We consider this an add-on adaptation. In the learning situation Inugait, she gave each student a plate. She put the bones chart in the middle of the students as they sat in a circle on the floor. She gave some students a bone and they had to put it on the corresponding bone on the chart. Then, she gave each student a bone, and they had to write their name and the name of the bone in the middle of the plate. The students put their bone on the plate, and they all put their plates next to the corresponding bone on the chart. Each student then picked a bone from a mitten using a string. This was part of the learning situation Inugait. The students put the bones they got in either their plate, or in another one if they already had the bone picked. They had to put the bones representing the seal in each plate. The teacher was sensible to the citizenship aspect of the learning situation, in particular by the fact that students had to learn about the traditional life in the community and about mutual aid. As learning intentions, she wanted her students to share the food they got, and see the importance that all members of the community had food to survive. Her representation of the situation was that the game Inugait represented an Inuit's way of life and the values associated to it. Her sensitivity to the citizenship context lead her to make a major adaptation to her role, but a minor adaptation to the overall project since it didn't affect the task's instructional goals.

The researcher also made a breach in the research agreement so the teacher would stay aligned with the mathematical instructional goals of the research project. She changed her role from an observer to a coach in the learning situation Inugait by asking the teacher to write the students' results on the blackboard while the task was being enacted with the students. It was an add-on adaptation from the researcher since she added a new role. She was sensitive to the mathematical context. She wanted to support student's development of probabilistic reasoning. Her representation was that students needed a visual support to think about the data. She was also concerned about the data she was gathering on students' probabilistic reasoning, which was the major goal of the funded research project. She was concerned about her responsibilities as a researcher. Changing her role might be seen as a minor adaptation in the research project, but we consider it as a major one in terms of students' learning. After that episode, the researcher participated more actively in the enactment, with the agreement of the teacher.

\subsection{Breaches in the Goals Planned and Enacted}

The researcher' goals changed during the enactment. It was an add-on adaptation, because she added a new goal. When she observed the changes made by the teacher, she tried to understand the reasons behind them. She thus added a new goal to the research project: studying the teacher's 
actions during the enactment of the learning situations designed for the project. She informed the teacher that she wanted to know why she was doing things, but didn't explicitly say that it was a new goal for her in this research project. The researcher was sensitive to the mathematical context. She wanted the teacher to enact the learning situations planned out. Her representation was that students were not learning about probability, thus not developing their probabilistic reasoning. She was also concerned about getting the data on students' probabilistic reasoning, which was the major goal of the research project. Changing her goal seemed to be a major adaptation for the whole research project, and might be also considered as a major one in terms of students' learning.

\section{Discussion}

Results show that this collaborative research project between the teacher and the researcher presented some breaches in some components of the research agreement. We remind the reader that designing and teaching lessons was the core of the project. During the first phase of the project, the co-situation, the collaborators' goals were defined, but they shifted as the project progressed. The teacher said that her goal was to learn more mathematics, but her actions shifted to focus more on the sociocultural aspects of Inuit traditions, and in one case on the citizenship context. A strong need to understand what's happening emerged for the researcher. Thus, the results addressed this need from her point of view, which might have implicit biases. Thus, the results also shed some light on the different breaches in the research agreement. Those breaches appeared to be in the choice of the resources, pedagogy and tasks used during the enactment of the lesson, on the roles, and the goals of the collaborators. For each breach, a discrepancy between what was planned and what was enacted appeared. In fact, four different categories of discrepancies emerged from our results.

The first category can be defined as " $x$ was planned and $x^{1}$ was enacted" $\left(x \rightarrow x^{1}\right)$. In this category, the breaches were situated in the choices of the resources used. The adaptations were substitutions and were considered as minor changes from what was planned because they remained aligned with the lesson plan, and the learning of probability was not affected. The teacher stayed in the sociocultural context like she was supposed to, and the adaptation was aligned with the whole project: to play Inugait.

The second category can be defined as " $x$ was planned and y was enacted" $(x \rightarrow y)$. The breaches in this category were situated in the choices made for the pedagogies used or for the tasks enacted. The adaptations were avoidances for the pedagogies chosen and structural for the tasks enacted. These adaptations were major for both cases and resulted in the teacher and the students staying in the sociocultural context and not being able to reach the mathematical context. The choices were not aligned with what was planned. All these adaptations were aligned with the whole project: to play Inugait

The third category can be defined as " $x$ was planned and nothing was enacted" $(x \rightarrow 0)$. In this category, the breaches were situated in the tasks. In this case, some important actions were planned in the lesson plan, but they were not done at all. Extreme avoidance adaptations were made, and therefore, the teacher and her students remained in the sociocultural context and were not able to reach the mathematical context. The choices were not aligned with what was planned. All these adaptations were aligned with the whole project: to play Inugait

The fourth category can be defined as "nothing was planned and b was enacted" $(0 \rightarrow b)$. In this category, breaches were situated in the roles and the goals of the collaborators. Some add-on and structural adaptations were made. The collaborators modified their initially planned roles, such as being recorded in the sociocultural context of the first learning situation for the teacher, and participating in the discussion with the students to bring the teacher in the mathematical context for the researcher. The researcher also added another goal: studying the breaches in the research agreement. Those add-on adaptations were major and were aligned with the research project. In the case of the structural adaptation made by the teacher, she designed and enacted a new activity using bones. It was a minor change in the whole process, because it was aligned with the whole 
project: to play Inugait. What was interesting is that the teacher was situated in a citizenship context. This context was important for her that she stepped in and designed something that was missing for her. Table 2 presents the discrepancies that created the breaches in the research agreement. The gray zone represents the researcher's discrepancies and the bolded borders represent the discrepancies that impacted the most the research project.

Table 2

The discrepancies that created the breaches in the research agreement

\begin{tabular}{|c|c|c|c|c|c|c|}
\hline & Discrepancies & $\begin{array}{c}\text { Collaborative } \\
\text { phase }\end{array}$ & Breaches & Adaptations & $\begin{array}{c}\text { Context } \\
\text { according to } \\
\text { Savard (2015) }\end{array}$ & Alignment \\
\hline 1 & $x \rightarrow x^{1}$ & $\begin{array}{l}\text { Lesson } \\
\text { enactment, } \\
\text { Cooperation }\end{array}$ & Resources & $\begin{array}{l}\text { Substitutive } \\
\text { minor }\end{array}$ & Sociocultural & Aligned \\
\hline \multirow[t]{2}{*}{2} & \multirow[t]{2}{*}{$x \rightarrow y$} & $\begin{array}{l}\text { Enacting } \\
\text { lessons, } \\
\text { Cooperation }\end{array}$ & Pedagogy & $\begin{array}{l}\text { Avoidance } \\
\text { major }\end{array}$ & \multirow{2}{*}{$\begin{array}{l}\text { Sociocultural } \\
\text { instead of } \\
\text { mathematical }\end{array}$} & \multirow{2}{*}{$\begin{array}{l}\text { Not aligned } \\
\text { with what } \\
\text { was } \\
\text { planned: } \\
\text { aligned } \\
\text { with the } \\
\text { project to } \\
\text { play Inugait }\end{array}$} \\
\hline & & $\begin{array}{l}\text { Planning, } \\
\text { Co-situation }\end{array}$ & Tasks & $\begin{array}{l}\text { Structural } \\
\text { major }\end{array}$ & & \\
\hline 3 & $x \rightarrow 0$ & $\begin{array}{l}\text { Lesson } \\
\text { enactment, } \\
\text { Cooperation }\end{array}$ & Tasks & $\begin{array}{l}\text { Avoidance, } \\
\text { major }\end{array}$ & $\begin{array}{l}\text { Sociocultural } \\
\text { instead of } \\
\text { mathematical }\end{array}$ & $\begin{array}{l}\text { Not aligned } \\
\text { with what } \\
\text { was } \\
\text { planned: } \\
\text { aligned } \\
\text { with the } \\
\text { project to } \\
\text { play Inugait }\end{array}$ \\
\hline \multirow{4}{*}{4} & \multirow{4}{*}{$0 \rightarrow b$} & $\begin{array}{l}\text { Role (teacher) } \\
\text { Cooperation }\end{array}$ & Role & $\begin{array}{l}\text { Add-on } \\
\text { major }\end{array}$ & Sociocultural & \multirow{2}{*}{$\begin{array}{l}\text { Aligned } \\
\text { with the } \\
\text { whole } \\
\text { project }\end{array}$} \\
\hline & & $\begin{array}{l}\text { Role (teacher) } \\
\text { Co-situation } \\
\text { design }\end{array}$ & Role & $\begin{array}{l}\text { Structural } \\
\text { minor }\end{array}$ & Citizenship & \\
\hline & & $\begin{array}{l}\text { Role } \\
\text { (researcher) } \\
\text { Cooperation }\end{array}$ & Role & \multirow[t]{2}{*}{$\begin{array}{l}\text { Add-on } \\
\text { major }\end{array}$} & \multirow[t]{2}{*}{ Mathematical } & \multirow{2}{*}{$\begin{array}{l}\text { Aligned } \\
\text { with the } \\
\text { whole } \\
\text { project }\end{array}$} \\
\hline & & $\begin{array}{l}\text { Goals } \\
\text { (researcher) } \\
\text { Cooperation }\end{array}$ & Goals & & & \\
\hline
\end{tabular}

The adaptations coming from this study differ from the adaptations identified by DeBlois \& Maheux (2005). In this study, the teacher and the researcher, not preservice teachers, made the adaptations. A teacher with many years of experience participated, and both collaborators were studied. Another major difference from Deblois and Maheux's (2005) study is that the adaptations made by the collaborators emerged from their representations of the situations during the enactment, not according to students' contributions or their epistemological stances.

We think that the breaches in the research agreement were possibly influenced by four reasons: the concept of probability not fully mastered by the teacher; the students in the class; the impact of 
the project on the community; and the influence of the curriculum, i.e. counting, doing subtraction and multiplication, and the importance of language arts.

All avoidance adaptations and the majority of structural adaptations made by the teacher happened because her representations on probability didn't seem related to randomness and variability. Those adaptations constitute the second and the third categories mentioned above where the changes were major in terms of students' learning of probability. The teacher didn't seem familiar with this concept. The concept of probability was introduced earlier in the cosituation phase. The researcher discussed randomness and uncertainty with the teacher. She tried to support the teacher's understanding of probability by showing a probability line, and have her talk about her resources to teach probability. However, it appeared that this concept needed more time to be properly understood. The teacher, inspired by the examples of card games given by the researcher when talking about traditional games, was looking for similar activities. She thus had the idea to have her students play something similar to a poker game where her students would have to get cards from their neighbours and make pairs. Her representation of probability was linked to poker games. The teacher mentioned this during an interview, but only after the lesson was enacted in class. Before that interview, the teacher would always reply, "I know" and talk about the activities on probability she taught in the past when the researcher brought the topic of probability during the meetings. However, when the researcher compared the frequential probability with the theoretical probability at the end of the learning situation Makitaguk, we noticed that the teacher made a reaction in the video. It seemed like she discovered new representations and got a more conceptual understanding of probability. This result seems to confirm what Konold (1991) and Briand (2005) point out: that people might have different explanations in interpreting random phenomena.

In hindsight, the teacher's instructional goals for that activity were linked to learning mathematics. However, she did not bring the mathematical context of probability in the learning activities; she remained in the sociocultural context. She did bring other mathematical concepts related to arithmetic (counting and subtraction mostly). These concepts are considered important at the elementary school level, and the teacher was sensitive that some of her students were struggling with subtraction. However, the concept of probability was planned to be the central concept in this collaborative research project. Since the teacher didn't explicitly express her need to understand the concept of probability, and since the researcher didn't want to offend her by giving her detailed explanations, the concept of probability was not the main topic to be taught. It was difficult for the teacher to recognize the concept of probability when it was present in the lessons. Evidence that supports this observation was that the teacher neglected to ask why when students answered her questions during the enactment. Asking why was fundamental since one of the main goals of the learning situations was to focus on eliciting student's thinking by having them justify their answer to the questions asked or on their results of their experimentations. The "why" would help support the notions of randomness and variability in students for the events discussed in the learning situations. For instance, the teacher was able to launch an activity on probability when she asked her students to draw a bone card out of the mitten and record the results on a piece of paper. However, she didn't use the data to initiate a class discussion nor talked about them during the lesson. She collected the data for the sake of the research agreement because it was agreed upon during the co-situation phase. She didn't use the data for students' mathematical learning. Also, the collaborators decided to do some mathematical operations with cards, such as addition and multiplication during the planning of the learning situation Saunitt. The teacher however didn't take the opportunity to do these mathematical activities with the students. During the interview after the lesson, she revealed that she changed her mind because she found that her students were tired of playing with the cards. Instead, she switched to a language arts activity with the cards because she thought they were doing mathematics before. She felt her students were getting tired of doing mathematics. Language arts are also a subject matter that is considered important at the 
elementary school level. These instances show that the teacher was sensible to her students and the curriculum.

The teacher's representation of the game Inugait played also had a major impact on the research project. She mentioned during an interview that she learned this game in her initial teacher training by a renowned woman in the community. This woman taught their traditional culture many years ago. She even recorded a film about the game, and it was that video that was used during the learning situation Inugait. Her representation about the game was that it was an important knowledge to know. It is challenging to play, because players have to know the name of the bones and their symbolic representation in the game. She was sensible about supporting students in learning the name of the bones and their traditional culture. As mentioned during an interview, the teacher was concerned that young Inuit didn't know how to fish and hunt, thus they were losing their traditional culture. In addition, the activities done in class got students to ask their parents about the bones, the games and their traditional way of living. Many of the parents didn't know about the game, so the students started asking their grandparents, who asked the Elders and to other members of the community. The teacher received many positive comments about the project because it celebrated their culture in a concrete manner. The sociocultural aspects, and the citizenship context became more important as the project progressed. This is possibly why the teacher changed her role and designed an activity that was centered in the citizenship context according to Savard's (2008) model and thus created a structural adaptation (fourth category). We can hypothesize that, given the impact the project had on the community, the teacher might have added a new goal in the research project: to make students be more aware and sensible of their culture. This possible new goal was not discussed with the researcher. However, the interviews seem to point to that direction, but no definite conclusions can be made at this time. We think that the fact that: parents mentioned that their boys wanted to go hunting with real dogs and that their girls wanted to sow; and students began to question the teacher about things they never seen before (for instance if the freezer that kept the animals frozen in the game really existed) (mentioned during an interview), possibly influenced her to remain in the citizenship context instead of the mathematical one. Another reason that possibly supports this is that she mentioned during an interview that her students listened and wanted to learn more from her. During the project, she felt a closer bond between her and her students.

On the other hand, the researcher's representations of mathematics led her to change her role and her research goals. She had two important goals; the first one focussed on students' learning of probability while the second emphasized the research agreement. To study the last one, she wanted to know in detail what the teacher's learning intentions were. It appeared that the teacher's learning intentions were unclear for herself and also the researcher. The teacher was able to prepare all the materials needed to enact the learning situations. However, when the researcher directly asked her about her learning intentions (why did you want to do that? Or why did you do this?), she was not able to talk about them. She either said nothing or directed the conversation around the importance of seals to Inuit and the Inugait game. When the researcher drew a probability line on the blackboard to talk about the meaning of probability, she said that she knew about it and ended the discussion. It seemed also that even if the initial learning intentions seemed to be understood implicitly by the teacher, her actions went in different directions from what was planned with the researcher.

The researcher made add-on adaptations in the cooperation phase to target the mathematical goals of the research project. She wanted to bring the teacher in the mathematical context. It was an essential need for the researcher that the students deeply understood the mathematics involved in the learning situations and not stay at a superficial level on cultural differences. Her milieu was always different from the teacher's milieu. For instance, in the co-situation phase, she was a guest at the school, so she was more sensible to different aspects of the school life than the teacher. Even if the community was also a new milieu for the researcher, it was a broader one for the teacher. In the cooperation phase, the researcher observed the teacher in action with her students. She had a 
more "meta" look of the situation, which was different from the teacher. In fact, the researcher's role was defined in the co-situation phase, but she created a breach in the research agreement in the cooperation phase. The cooperation phase was a rich milieu for both collaborators. Even if the co-situation is the place to design the lesson, our study showed that the design (co-situation) and not only the planning (cooperation) might have to be done between the lessons. There is an iterative move between the two phases because the research agreement needs to be renegotiated according to the milieu and the collaborators' representations in the cooperation phase. In this case, the collaborators needed to redefine their roles and their goals and actions, but some was done without explicitly discussing with the other collaborator before enacting the adaptation. In this case, the researcher created a breach in the research agreement when she asked the teacher to record the students' results. This was a breach because the collaborators had to renegotiate the research agreement after. They agreed that the researcher would team-teach with the teacher. Therefore, we can say that the two first phases of the collaborative research are neither linear nor static, but dynamic.

The negotiation and the renegotiation of the research agreement are also part of this dynamic process, initiated by the collaborators' representations of the situations, and the elements they are sensible to in their milieu. This renegotiation of the research agreement where the researcher cotaught with the teacher supported students to get in the mathematical context of the learning situations, thus helping the researcher meet her goal related to probabilistic reasoning. We think that it is also possible to create breaches in the coproduction phase. But it was not possible to study the research agreement for this phase because the teacher declined the researcher offer to participate in the analysis of the data. Figure 1 shows the process between the three phases of the collaborative research.

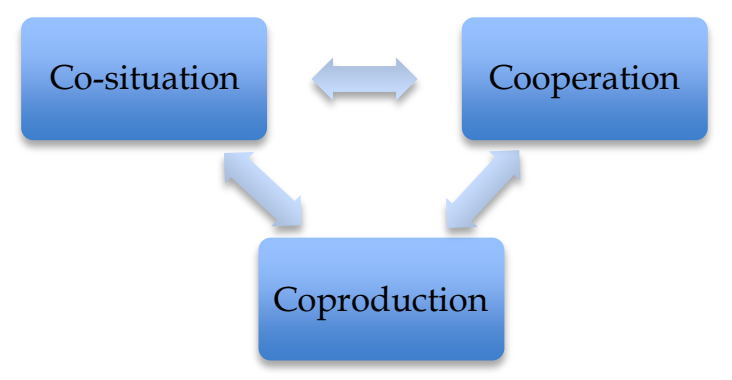

Figure 1. Our model of the collaborative research process

As Jaworski (2005) pointed out, in collaborative research, although each collaborator should have an equal role, teachers are not researchers. They can however be initiated to research during the process. Also, since the researcher gets the funds and is the main author of the project, she can be perceived to be the authority figure. This can create a possible hierarchical view of the research project collaboration, which could have possibly been the case for this particular project because of the cultural differences. Since the researcher was white, the teacher could have perceived her as a high authority because whites are assumed to possess all the knowledge according to the Inuit culture.

We also noted that creating a collaborative research involves a willingness to be innovative and try something new from all the collaborators. The teacher brought something new in class by bringing the Inuit culture in the classroom. However, when it came to mathematics, she didn't take a new direction in regard to learning probability. However, we think she thought she did take a new direction. She went in a direction that was not related to the mathematical concept, and this result had an impact on students' learning. On the researcher's part, she took a risk by introducing a teaching approach that could or could not have been familiar to the teacher so that her students 
developed a more conceptual understanding of probability. The researcher's motivation for trying something new was so that her students didn't think that probability was just something related to personal beliefs or something that comes from faith. The fact that the collaborators tried something new implied spending time and energy for the project. It also implied trustiness and confidence between the collaborators. Each of them was out of their comfort zone: the research agreement must be created and represent a safe environment for them. In this project, the teacher had also a very sensitive point: her community's regard.

A collaborative research project cannot exist without the input of the teacher. The researcher is the expert with the theoretical knowledge, and the teacher should take advantage of her expertise to reach her professional development goals. The teacher has her practical expertise and the researcher needs that knowledge and the teacher's reflexive contribution in order to link everything together. A clear communication of each collaborator's needs is thus necessary and even mandatory for this type of research to be successful (Jawoski, 2005). Otherwise, it may result in breaches in the research agreement. Since both collaborators had to communicate in their second language, we think that the meaning of messages expressed by both of them could have influenced some breaches in the research agreement. Some teachers might believe that by expressing their needs, they put themselves in a situation of weakness. This implies that the researcher then becomes the referenced person when in fact the teachers' needs may be met with the researcher's help along with her contribution. As we mentioned before, the researcher might have the theoretical expertise in the field, but she needs the teacher's practical expertise in order to create a whole that will be implemented in the classroom. Figure 2 represents a visual representation of our model.

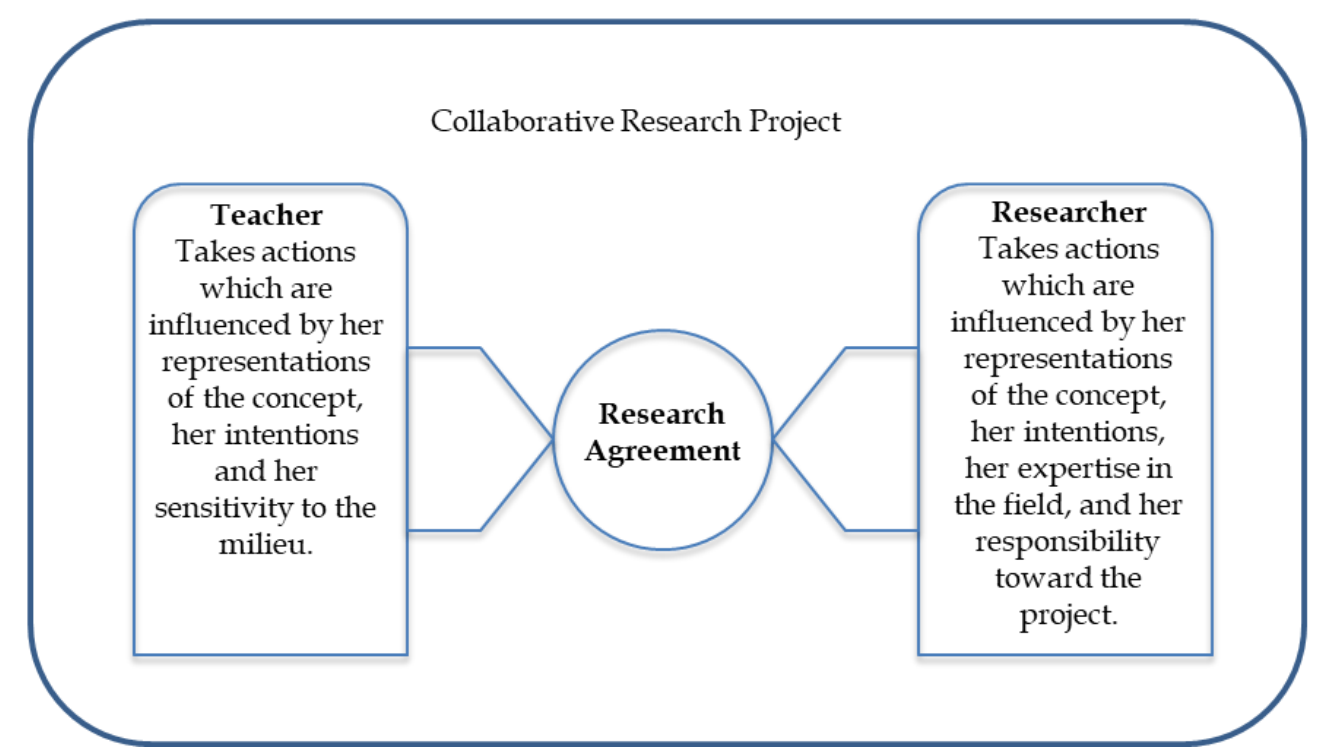

Figure 2. Our model of a collaborative research project

The conceptual framework used in this article however has some limitations. In this particular case, it was very difficult to interpret the teacher's instructional goals for the learning situations because of the differences in the collaborators' understanding of the concept of probability. Also, after analyzing the data, we realised that the researcher had two separate responsibilities when it came to the research agreement: the student's learning, and also teacher's learning. During the cosituation phase, the responsibilities were more dedicated toward students' learning since the project emphasised the students' development of probabilistic reasoning, but during the cooperation phase, the responsibilities were shifted more toward the teacher's learning because her actions would have an influence on what students learn and how the theoretical and practical goals of each collaborator are met. The research agreement had an influence on the actions taken by the collaborators. 
We believe that it would be beneficial to use this model again for future collaborative research projects to highlight some necessary conditions for an effective collaborative research and its influence on mathematics, but modifications to the research process should be made following the analysis of the data from this project.

The researcher did not audio or video-record the initial planning of the learning situations between the teacher and the collaborators. The school board consultants were not comfortable and because it was not the initial goal of the project to study this phase, the researcher only took field notes. It is thus possible that the teacher had preliminary representations about probability, but the researcher was not able to observe them and work on them. The fact that the lesson plans were also written in the second language of both collaborators could have possibly influenced the representation and the learning goals of both collaborators. The translation of the videos was also considered as a limit of the research because the professional translator did not translate everything that was said, especially with students. On many occasions, many students were speaking at the same time.

It is also important that we did not consider elements related to classroom management in our analysis of the discrepancies. We find that this is part of the teacher's responsibilities. She is the expert when it comes to classroom management since she knows her students and the adaptations are made according to her knowledge of students. Since we are not assessing the teacher, and that cases like this do not influence the research agreement, we thus disregarded these cases from our analysis.

In reflecting on the collaborative research project itself as a whole, we must acknowledge that these results were interpretations made by the researcher and the co-author of the article. Both authors are White people with English as a second language. Although the participant was invited to participate in all three phases of the collaborative research project, she declined the invitation to participate in the third phase which consisted of analyzing the data. Thus, in this article, we could only present the interpretation of one side of the team, the researchers. It is possible that the participating teacher would have had a different interpretation of the breaches we saw in the design and enactment of the project.

In addition, the roles of each member in the collaborative research project, although they should have equal say in the project, may be viewed differently by each member depending on their culture and experiences. For instance, how do the participants (the school board consultants and the teacher) really see the role of the researcher who is also an expert in mathematics education? It is possible that these views might have caused biases in the data. Walshaw (2013) discusses these ethical issues of identity and power that may influence research results between members of a project with different cultural experiences and expertises.

\section{Conclusion}

The results of this collaborative research show that breaches in the research agreement were present in the resources, the pedagogies used, and the tasks implemented during the enactment of the learning situations created for this collaborative research, which lead to minor substitution, major avoidance, and major structural tasks on the teacher's behalf. Out of those three breaches, we found that the last two (pedagogies and tasks used) had a major impact on the project because students were losing the opportunity to learn about probability, which was the mathematical core of the project. The adaptations made by the teacher were keeping her from reaching the mathematical context of the learning situations, thus remaining in the sociocultural context.

The results also show a breach in the goals set for the project. It was clear that the researcher added a new goal, but it is highly possible that, based on the impact this project had in the community, the teacher added goals too. Breaches were also present in the roles played by both collaborators. The teacher designed a task that focussed on the citizenship context of living in their community, while the researcher intervenes during an activity and co-taught with the teacher to 
bring the sociocultural aspects of the learning situations into a mathematical context. This role change by the researcher helped attain the mathematical goal of the project.

As for the goals initially set by the collaborators, we feel that they were met to a certain point. The teacher wanted to learn more about mathematics, and we believe that she learned more about probability at the end of the project. We think that her representations of the concept of probably caused some breaches in the research agreement. On the researcher's part, she was able to maintain her first goal, but she had to step in as a co-teacher to be able to maintain her goal. We will write another article that will focus on the probabilistic reasoning of grade 3 Inuit students that resulted from this project. As for this goal, which was the focus of the article, we think that the four categories of discrepancies that we found in our results and mentioned above can be applicable in any collaborative research project between teachers and researchers.

This collaborative research was built using Desgagné's (2007) phases. Although we agree with the three phases, the results of this research revealed that they should not be followed linearly. It is sometimes important while in the cooperation phases to return to the co-situation phase especially when the interpretations and representations of the collaborators are largely different. Some "replanning" might be beneficial or even necessary depending on the situations that occurred during the enactments. A new research agreement might have to be created between the collaborators. Not only was this collaborative research between a grade 3 Inuit teacher and a researcher in mathematics education created as a mean of professional development, this project was conducted in a context where the cultural difference between the two collaborators were important. Although some might believe that such projects are unfeasible because of the cultural differences, we think that it is possible, although certain steps could be important to implement during the co-situation phase to facilitate the process. First, we strongly suggest that all collaborators are familiar and confortable with the mathematical concepts that will be the core of the project. Some workshops could be added to make sure that all the collaborators will be able to recognise the concepts and ideas in the lesson plans and know how to challenge the students with the ideas. This could be done by researchers since usually, they are known to be the content expert. Also, this recommendation should be considered even in contexts where the cultural differences are absent. Second, it would be important to take the time and discuss the different milieu and cultures of every collaborator involved in the project. Since the worlds of teachers and researchers are different, it would be beneficial that each collaborator be aware of the other's milieu. For instance, the teacher could take the time to talk about the school, her class, her classroom management, and the successes and challenges she faces. The researcher could discuss in details the rational of her research. And together, the collaborators could discuss their cultures and find options that would benefit both sides. Following the two recommendations is further exploiting every collaborator's expertise and doing so could possibly reduce issues in a collaborative research project and maintain a stronger research agreement between the collaborators. More studies are needed to confirm this hypothesis.

\section{Acknowledgements}

This project was funded by Fonds de Recherche du Québec, Volet Culture et Société. We want to thank Terry Wan Jung Lin for her support.

\section{References}

Ball, D. L., \& Forzani, F. M. (2009). The work of teaching and the challenge for teacher education. Journal of Teacher Education, 60(6), 497-511.

Brun, J., \& Conne, F. (1990). Analyses didactiques de protocoles d'observation du déroulement de situations. Education et Recherches (3), 261-285.

DeBlois, L. (2009). Les contextes et les besoins à l'origine de la recherche collaborative. Annales de Didactique et de Sciences Cognitives, 14, 219-229. 
DeBlois, L., \& Maheux, J.-F. (2005, May). When things don't go exactly as planned: leveraging from student teachers' insights to adapted interventions and professional practice. Paper presented at the The 15th International Commission of Mathematical Instruction, Aguas De Lindoia, Brésil.

Desgagné, S., Bednarz, N., Couture, C., Poirier, L., \& Lebuis, P. (2001). L'approche collaborative de recherche en éducation: un nouveau rapport à établir entre recherche et formation. Revue des Sciences de l'Éducation, 27(1), 33-64.

Goodchild, S. (2007). An activity theory perspective of didacticians' learning within a mathematics teaching development research project. Paper presented at the Congress of the European Soviety for Research in Mathematics Education, CERME 5, Larnaca, Cyprus.

Goodchild, S., \& Jaworski, B. (2005, July). Using contradictions in a teaching and learning development project. Paper presented at the 29th Conference of the International Group for the Psychology of Mathematics Education, Melbourne, Australia.

Hirn, C., \& Viennot, L. (2000). Transformation of didactic intentions by teachers: the case of geometrical optics in grade 8. International Journal of Science Education, 22(4).

Jaworski, B. (2005). Learning communities in Mathematics: Creating an inquiry community between teachers and didacticians. Research in Mathematics Education, 7(1), 101-119.

Jaworski, B. (2007, February). Theory in developmental researchin mathematics teaching and learning: Social practice theory and community of inquiry as analytical tools. Paper presented at the Congress of the European Soviety for Research in Mathematics Education, CERME 5, Larnaca, Cyprus.

Jaworski, B., \& Goodchild, S. (2006, July). Inquiry community in an activity theory frame. Paper presented at the 30th Conference of the International Group for the Psychology of Mathematics Education, Prague, Czech Republic.

McIntyre, D. (1997). The profession of educational researcher. British Educational Research Journal, 23(2), 127140.

Raymond, A.M. \& Leinenbach, M. (2000). Collaborative action research on the learning and teaching of algebra: A story of one mathematics teacher's development. Educational Studies in Mathematics, 41(3), 283307.

Savard, A. (2017). Implementing inquiry-based learning situation in science and technology: What are elementary school teachers' learning intentions about mathematics? Philosophy of Mathematics Education Journal, 32 .

Savard, A. (2015). Making decisions about gambling: The influence of risk on children's arguments. The Mathematics Enthusiast, 12(1,2 \& 3), 226-245.

Savard, A., Manuel, D. \& Lin, T. W. J. (2014). Incorporating culture in the curriculum: the concept of probability in the Inuit culture. In Education, 19(3), 152-171.

Savard, A. \& Corbin, N. (2012). La communauté d'apprentissage professionnelle comme dispositif d'implantation de la démarche d'investigation en science et technologie au primaire. Revue Canadienne de l'éducation, 35(2), 355-378.

Savoie-Zajc, L., \& Descamps-Bednarz, N. (2007). Action research and collaborative research: their specific contributions to professional development. Education Action Research, 15(4), 577-596.

Stavrou, S. G., \& Miller, D. (2017). Miscalculations: Decolonizing and antioppressive discourses in indigenous mathematics education. Canadian Journal of Education/Revue canadienne de l'éducation, 40(3), 92122.

Wittmann, E. C. (1998). Mathematics Education as a "Design Science". In A. S. J. Kilpatrick (Ed.), Mathematics Education as a Research Domain: A Search for Identity (pp. 87-103). The Netherlands: Kluwer Academic Publishers

Kingsley, L. \& Romine, R. (2014). Measuring teaching best practice in the induction years: Development and validation of an item-level assessment. European Journal of Educational Research, 3(2), 87-109.

Walshaw, M. (2013). Post-structuralism and ethical practical action: Issues of identity and power. Journal for Research in Mathematics Education, 44(1), 100-118. 